\title{
RESISTÊNCIA À CORROSÃO DE AÇOS ELETROGALVANIZADOS FOSFATIZADOS E PINTADOS
}

Evandro de Azevedo Alvarenga ' José Geraldo Moreira ${ }^{2}$

Vicente Tadeu Lopes Buono ${ }^{3}$

\section{Resumo}

Avalia-se a influência da massa de zinco na resistência à corrosão de aços eletrogalvanizados, fosfatizados e pintados. Foram usados dois aços eletrogalvanizados com substratos distintos: um de aço carbono convencional, denominado Usigalve, e outro de aço USI-R-COR-III, com características de resistência à corrosão atmosférica, designado Usigalve/Plus. A resistência à corrosão foi determinada por meio de testes acelerados e não-acelerados de corrosão, utilizando-se câmaras de testes cíclicos e estações de corrosão atmosférica industrial e marinha da Usiminas. Os parâmetros medidos foram o avanço médio e a penetração máxima da corrosão, empregando-se técnicas de análise de imagem. Este estudo mostra que a massa de zinco exerce papel preponderante na resistência à corrosão atmosférica dos aços eletrogalvanizados fosfatizados e pintados. Além disso, verifica-se também que é perfeitamente possível utilizar espessuras de camadas de zinco menores, sem comprometer a resistência à corrosão do material, desde que o substrato metálico apresente propriedades de resistência à corrosão atmosférica, contribuindo assim para melhorar a conformabilidade dos aços revestidos com zinco.

Palavras-chave: Resistência à corrosão; Eletrogalvanização; Pintura; Conformação.

\section{CORROSION RESISTANCE OF PHOSPHATIZED AND PAINTED ELECTROGALVANIZED STEELS}

\begin{abstract} corrosion contributing for the improvement of the formability of zinc coated steel.

Key words: Corrosion resistance; Electrogalvanizing; Painting; Formability.

\section{INTRODUÇÃO}

Uma das maiores mudanças ocorridas nos últimos anos em relação à aplicação do aço como elemento estrutural foi a utilização de aços revestidos com zinco para situações que exigem maior resistência à corrosão. $O$ consumo de zinco tem aumentado ano $\mathrm{a}$ ano. Os 21 países economicamente mais desenvolvidos são responsáveis por $86 \%$ da utilização global de zinco e somente a China contribui com $22 \%$ desse montante. A maior parte do zinco é destinada à produção de chapas galvanizadas, destacando-se como principais consumidores as indústrias automobilística (32\%), da construção civil (28\%) e elétrica/eletrônica (18\%).(1)
\end{abstract}

The influence of the mass of the zinc layer in the resistance to atmospheric corrosion of electrogalvanized steel sheets phosphatized and painted is evaluated. Two types of electrogalvanized steels were used: a carbon steel for drawing as metallic substrate, Usigalve, and other, Usigalve/Plus, having as substrate USI-R-COR-III, a steel resistant to atmospheric corrosion. Corrosion resistance was determined by means of accelerated and non-accelerated corrosion tests, using, respectively, chambers of cyclical tests and industrial and marine atmospheric corrosion stations of Usiminas. The measured parameters were the average advance and the maximum penetration of corrosion. Results show that the mass of the zinc layer has a strong influence in the atmospheric corrosion resistance of phosphatized and painted electrogalvanized steel sheets. Moreover, it wis also verified that it is possible to use lower masses of zinc layer, without compromising the corrosion resistance, when the metallic substrate presents characteristics of resistance to atmospheric

A produção de aços revestidos com zinco no Brasil iniciou-se há algumas décadas e atendia principalmente aos setores de distribuição, da construção civil, de tubos de pequeno diâmetro e de utilidades domésticas. A partir da década de 80 , as indústrias começaram a procurar por novas matérias-primas para a fabricação de produtos mais duráveis, com maior resistência à corrosão e compatíveis com similares existentes no mercado internacional, encontrando nas chapas galvanizadas o material ideal para esse objetivo. Atualmente, a capacidade brasileira de produção de chapas reves-

\footnotetext{
' Engenheiro Químico, Dr.., Superintendência do Centro de Pesquisa e Desenvolvimento da Usiminas. Av. Pedro Linhares Gomes, 5.43I - Bairro Usiminas - 35160-900 - Ipatinga, MG. alvarenga@usiminas.com.br

${ }^{2}$ Técnico em Química, Superintendência do Centro de Pesquisa e Desenvolvimento da Usiminas, Av. Pedro Linhares Gomes, 5.43I - Bairro Usiminas - 35160-900 - Ipatinga, MG. Ipatinga, MG

${ }^{3}$ Físico, Dr., Professor Adjunto do Curso de Engenharia Metalúrgica. Departamento de Engenharia e de Materiais da UFMG. Rua Espírito Santo, 35 , sala 206 - Centro. 30160-030 - Belo Horizonte, MG. vbuono@demet.ufmg.br
} 
tidas com zinco é de 2.740 mil t/ano, dividida praticamente entre a CSN (54\%), a Usiminas (28\%) e a Vega do Sul (I8\%). No Brasil, o setor automotivo também é o grande responsável pela demanda de chapas revestidas, consumindo em 2005 cerca de 780 mil toneladas. A participação no mercado interno dos principais usuários nacionais de chapas revestidas com zinco pode ser vista na Figura I.

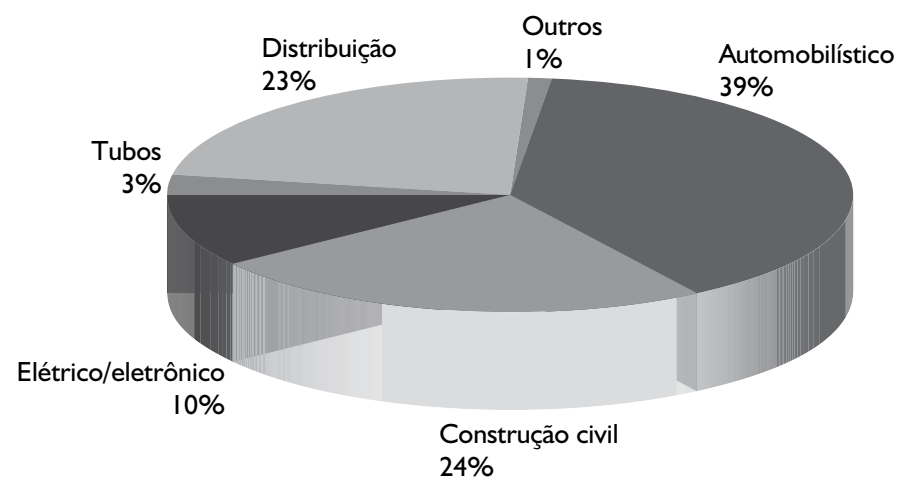

Figura I. Principais setores consumidores de chapas revestidas com zinco no mercado brasileiro. Fonte: Superintendência de Marketing do Sistema Usiminas, novembro/2006.

Um dos problemas que ocorre com a utilização de aços galvanizados pelo setor automobilístico é o desprendimento de revestimento, uma vez que as partículas de zinco podem causar defeitos superficiais nos painéis durante os processos de conformação. Esse desprendimento dá-se por dois fenômenos distintos: a formação de pós (powdering) e de lascas (flaking). Segundo alguns autores, ${ }^{(2-4)} \circ$ desprendimento de zinco durante a conformação de chapas eletrogalvanizadas é mais acentuado nos casos em que a camada de zinco é mais espessa e sua dureza mais elevada. Hisamoto et al. ${ }^{(2)}$ avaliaram o desprendimento de zinco em chapas eletrogalvanizadas e concluiram que a dureza do revestimento é o parâmetro mais significativo, principalmente quando a massa de zinco é superior a $40 \mathrm{~g} / \mathrm{m}^{2}$.

Estudos realizados pela Usiminas mostram que a camada de zinco influencia na conformabilidade (valor " $r$ " de Lankford) dos aços laminados a frio mais utilizados pela indústria automobilística (Figura 2). ${ }^{(5)}$ De acordo com essa figura, a maior queda no valor " $r$ " ocorre quando a espessura do revestimento é proporcionalmente

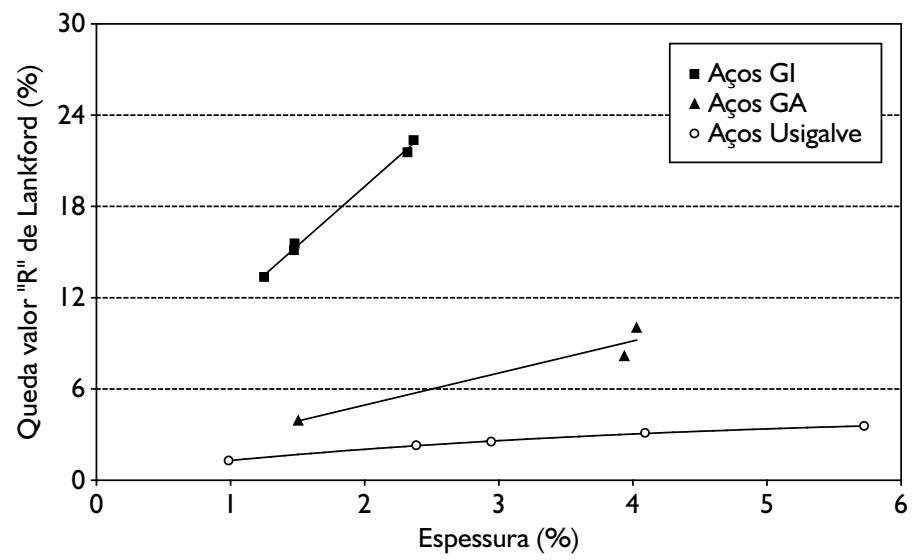

Figura 2. Efeito da camada de revestimento na queda do valor "r" de Lankford de aços revestidos com zinco. ${ }^{(5)}$ maior em relação à espessura do aço base. Em outras palavras, isso significa que, para uma mesma massa de zinco aplicada em aços de mesma qualidade, mas com espessuras diferentes, a queda no valor " $r$ " será maior para aquele aço base de menor espessura. Portanto, para melhorar a conformabilidade dos aços galvanizados para estampagem a camada de zinco deverá ser a menor possível. Esses resultados são válidos tanto para os aços eletrogalvanizados (Usigalve) como para os aços galvanizados a quente (Gl e GA).

No entanto, a redução da espessura da camada de zinco dos aços deve seguir um critério técnico embasado não só no benefício obtido durante a conformação, mas também no da resistência à corrosão do material. Ao se reduzir demasiadamente a massa de zinco pode-se comprometer a resistência à corrosão oferecida pelo material. ${ }^{(6)}$

Assim, apresentam-se neste estudo os resultados da influência da espessura da camada de zinco na resistência à corrosão de dois aços eletrogalvanizados produzidos pela Usiminas: os aços Usigalve e Usigalve/Plus, de forma a fornecer subsídios aos usuários na escolha da melhor massa de zinco para suas aplicações.

\section{MATERIAIS E MÉTODOS}

Foram preparados corpos-de-prova, nas dimensões de $100 \mathrm{~mm} \times 150 \mathrm{~mm}$ e espessura de $0,72 \mathrm{~mm}$ a $0,85 \mathrm{~mm}$, a partir de bobinas de aços carbono convencional, USI-R-COR-III , Usigalve e Usigalve/Plus . A fosfatização e a pintura dos corpos-de-prova foram feitas em uma indústria automobilística. ${ }^{(7)} \mathrm{A}$ espessura e a aderência da película seca de tinta foram determinadas de acordo com as normas NBR 10443 e NBR I I 003. A espessura média foi de $110 \mu \mathrm{m}$, com desviopadrão de $3 \mu \mathrm{m}$, e a aderência pelo método da tração(7) variou de I,54 MPa a 2,72 MPa, correspondendo ao "grau 0" pelo método da grade. Antes de cada teste de corrosão a película seca de tinta, relativa à face superior do corpo-deprova, foi danificada mecanicamente com uma ferramenta de usinagem com ponta de carbeto de tungstênio até atingir o metal base, conforme especifica a norma NBR 8754.

Os testes acelerados de corrosão realizados foram: testes cíclicos Ciclado I e GM 9540P/B e o de campo com aspersão de solução salina. $O$ teste Ciclado I foi desenvolvido pela Usiminas e consiste na exposição de corposde-prova em uma câmara para testes acelerados cíclicos de corrosão. Nessa câmara os corpos- 
de-prova recebem no primeiro dia a aspersão de solução salina de $\mathrm{NaCl}$ a $5 \% \mathrm{p} / \mathrm{v}$ e à temperatura de $35^{\circ} \mathrm{C} \pm 2^{\circ} \mathrm{C}$, durante 24 h. Do segundo ao quinto dia, os corpos-de-prova ficam expostos durante $8 \mathrm{~h}$ em ambiente com umidade relativa maior do que $95 \%$ e à temperatura de $40^{\circ} \mathrm{C} \pm 3^{\circ} \mathrm{C}$. Em seguida, a câmara de teste é desligada e aberta, permanecendo os corpos-de-prova na condição ambiente durante $16 \mathrm{~h}$. Nos sexto e sétimo dias, os corpos-de-prova voltam a ficar expostos em ambiente de laboratório com a câmara desligada e aberta. A duração do teste foi de $1680 \mathrm{~h}$, sendo expostos dez corpos-de-prova de cada aço estudado.

Os testes acelerados de corrosão GM 9540P/B e o de campo com aspersão de solução salina (atmosfera industrial) foram executados de acordo com as normas GM 9540P/B e ISO II 474. No primeiro foram expostos para cada tipo de aço dez corposde-prova e, no segundo, vinte e cinco corpos-de-prova, sendo a duração desses testes de $1920 \mathrm{~h}$ e três anos, respectivamente.

Para efetivar o teste não-acelerado de corrosão com exposição em atmosfera marinha seguiu-se a norma NBR 70II, empregando-se vinte e cinco corpos-de-prova para cada aço estudado.(7) Avaliações quantitativas e qualitativas desse teste foram feitas após três anos e quatro anos de exposição, respectivamente.

$\mathrm{Na}$ Tabela I é apresentada a taxa de corrosividade de cada um dos testes de corrosão realizados, em termos da perda de massa média de cinco corpos-de-prova de aço carbono convencional.

Tabela I. Taxa de corrosividade dos testes acelerados e não-acelerados de corrosão.

\begin{tabular}{|c|c|c|c|}
\hline Tipo de teste & $\begin{array}{c}\text { Tipo de solução } \\
\text { salina }\end{array}$ & $\begin{array}{c}\text { Período de } \\
\text { superfície } \\
\text { úmida (\%) }\end{array}$ & $\begin{array}{c}\text { Taxa de } \\
\text { corrosão } \\
\left(\mathrm{Kg} \mathrm{Fe} / \mathbf{m}^{2} . \mathrm{a}\right)\end{array}$ \\
\hline Ciclado I & $5 \% \mathrm{p} / \mathrm{v} \mathrm{NaCl}$ & 33 & 10,9 \\
\hline GM 9540P/B & $\begin{array}{l}0,9 \% \mathrm{p} / \mathrm{v} \text { de } \mathrm{NaCl}+ \\
0,1 \% \mathrm{p} / \mathrm{v} \text { de } \mathrm{CaCl}_{2} \\
+0,25 \% \mathrm{p} / \mathrm{v} \text { de } \\
\mathrm{NaHCO}_{3}\end{array}$ & 37 & 12,0 \\
\hline $\begin{array}{l}\text { Atmosfera } \\
\text { industrial com } \\
\text { aspersão salina }\end{array}$ & $5 \% \mathrm{p} / \mathrm{v} \mathrm{NaCl}$ & 50 & 2,5 \\
\hline $\begin{array}{l}\text { Atmosfera } \\
\text { marinha }\end{array}$ & não tem & 50 & 0,6 \\
\hline
\end{tabular}

Os valores de taxa de corrosão, apresentados na Tabela I, indicam que os testes acelerados cíclicos de corrosão foram os mais agressivos. Em seguida tem-se o teste acelerado de campo com aspersão de solução salina duas vezes por semana, que é cerca de quatro vezes menos agressivo que os testes cíclicos de corrosão. $O$ teste não-acelerado de corrosão, com exposição em atmosfera marinha, foi o menos agressivo dentre os testes realizados; no entanto, ele é considerado pela norma ISO 9223 como um teste severo por ser de exposição ao intemperismo natural.

A resistência à corrosão foi avaliada determinando-se o avanço médio e a penetração máxima da corrosão, conforme a norma NBR 8754. No primeiro caso, empregou-se técnica de análise de imagem, utilizando-se de câmara CCD (couple charge device) monocromática, placa para aquisição de imagem modelo $\mathrm{PCl}$ 1407, com software de aquisição e processamento desenvolvido pela Usiminas, fazendo-se o uso da linguagem de programação LabVIEW 6.I da National Instrument. No segundo caso, a penetração máxima da corrosão foi determinada em dez seções ao longo do risco e no sentido da espessura, utilizando-se técnica metalográfica e $\circ$ analisador de imagens Quantimet 600 HR da Leica Cambridge Ltd.

\section{RESULTADOS E DISCUSSÕES}

Conforme apresentado nas Figuras 3 e 4, o valor da penetração máxima da corrosão diminuiu à medida que aumentou a massa da camada de zinco dos aços. Constata-se por essas figuras que o desempenho do aço Usigalve/Plus foi melhor que o do aço Usigalve e isso é explicado pelo fato do substrato metálico do aço Usigalve/Plus ter características de resistência à corrosão atmosférica.

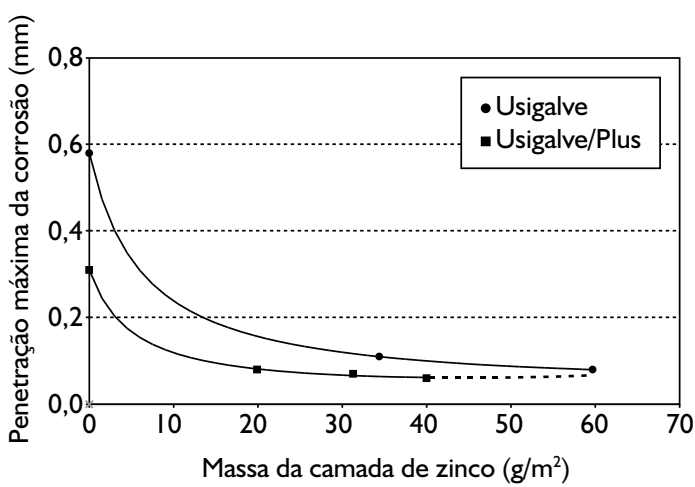

Figura 3. Resultados de penetração máxima da corrosão do teste acelerado cíclico de corrosão Ciclado I, após $1.680 \mathrm{~h}$ de exposição.

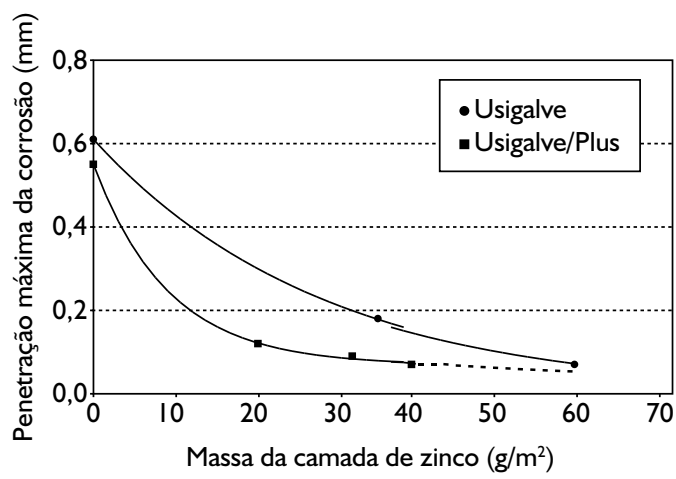

Figura 4. Resultados de penetração máxima da corrosão do teste acelerado cíclico de corrosão GM 9540P/B, após $1.920 \mathrm{~h}$ de exposição. 
Observa-se, ainda, que para massas de zinco acima de $60 \mathrm{~g} / \mathrm{m}^{2}$ os dois aços deverão ter desempenhos praticamente iguais, significando que a partir desse valor o mecanismo de corrosão predominante é por barreira. ${ }^{(7)}$

O avanço médio da corrosão também diminuiu com o aumento da espessura da camada de zinco dos aços, conforme evidenciado na Figuras 5 e 6. Por essas figuras verificou-se também que o desempenho do aço Usigalve/Plus foi melhor que o do aço Usigalve, mostrando que, além da massa de zinco, o substrato metálico também influencia na resistência à corrosão dos aços. Observa-se pelos resultados de avanço médio da corrosão que é perfeitamente possível reduzir a massa de zinco e manter, ao mesmo tempo, o desempenho do material em relação à corrosão, simplesmente substituindo o substrato metálico. A partir dos dados empregados na elaboração da Figura 6, verifica-se que, para obter um avanço médio da corrosão, por exemplo, de $1,5 \mathrm{~mm}$, são necessários $50 \mathrm{~g} / \mathrm{m}^{2}$ de zinco se o aço utilizado for o Usigalve (substrato de aço carbono convencional). Substituindo o material pelo aço Usigalve/Plus (substrato metálico com características de resistência à corrosão atmosférica) a massa de zinco necessária passa a ser de $40 \mathrm{~g} / \mathrm{m}^{2}$, correspondendo a uma redução de $20 \%$. A redução

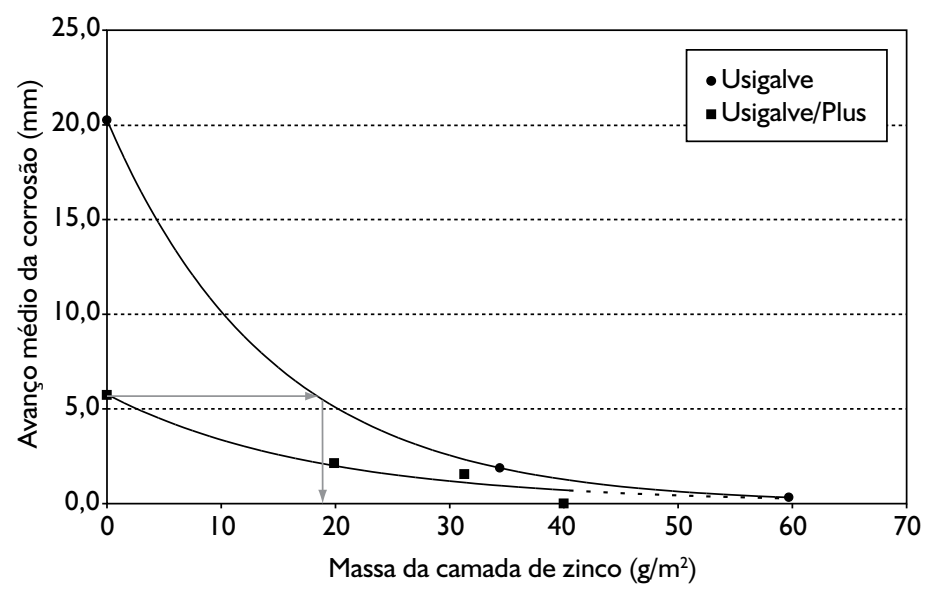

Figura 5. Resultados de avanço médio da corrosão do teste de campo com aspersão de solução salina de $\mathrm{NaCl}$ a $5 \%$ p/v duas vezes por semana, após três anos de exposição.

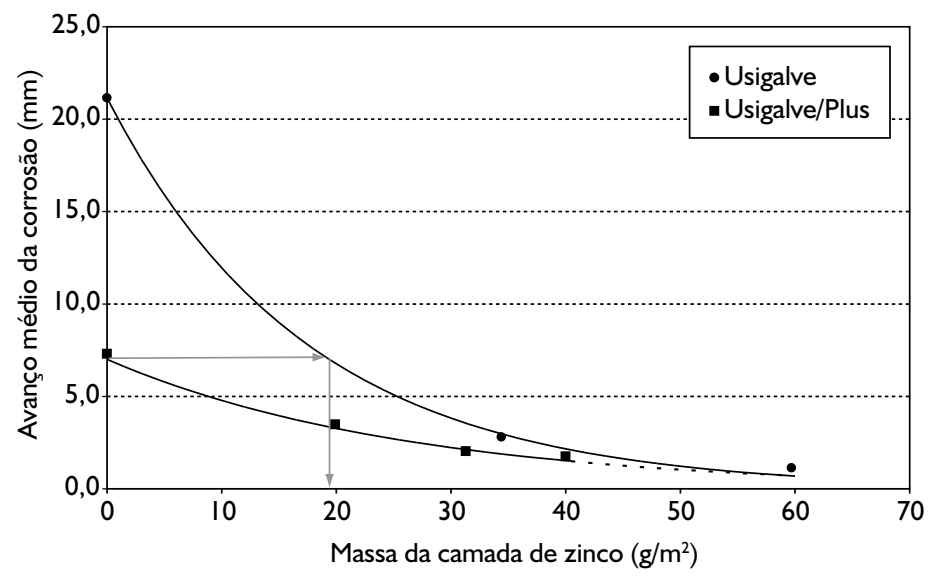

Figura 6. Resultados de avanço médio da corrosão do teste não-acelerado de corrosão, após três anos de exposição em atmosfera marinha. da espessura da camada de zinco proporcionaria um incremento na conformabilidade do material. Outro aspecto importante mostrado nas Figuras 5 e 6 é em relação à massa mínima de camada de zinco. Observa-se nessas figuras que, abaixo de um determinado valor de massa de zinco, em torno de $20 \mathrm{~g} / \mathrm{m}^{2}$, é melhor utilizar o aço USIR-COR-III sem revestimento de zinco do que o aço eletrogalvanizado, pois o desempenho desse aço em relação à resistência à corrosão tornou-se inferior ao do USI-R-COR-III.

É possível encontrar na literatura ${ }^{(8,9)}$ trabaIhos que referenciam essa questão, segundo os quais os resultados de ensaios não-acelerados de corrosão, realizados com aços revestidos com zinco ou com ligas à base de zinco, com massa de camada maiores do que $30 \mathrm{~g} / \mathrm{m}^{2}$, fosfatizados e pintados, foram satisfatórios quanto à proteção contra corrosão . Entretanto, com camada de zinco da ordem de $20 \mathrm{~g} / \mathrm{m}^{2}$ a resistência à corrosão ficou seriamente prejudicada, independentemente do tipo de camada de zinco. Para que a proteção por barreira oferecida pelo zinco seja efetiva, é necessário que haja uma camada de zinco entre o aço e o meio ambiente. Da mesma forma, para que a proteção catódica do zinco seja eficiente, é indispensável que os elétrons oriundos da dissolução do zinco corrente anódica — sejam em número suficiente para contrabalançar os elétrons necessários para que o aço não sofra corrosão - corrente catódica. Assim, quando a massa de zinco é muito baixa, os mecanismos de proteção por barreira e catódico não conseguem proteger $\circ$ aço, deixando-o prematuramente exposto às condições ambientais. Se o substrato metálico for de aço carbono convencional, sem características de resistência à corrosão, o processo corrosivo desenvolve-se sem dificuldade, formando óxidos volumosos e pouco aderentes. Com o tempo ocorrerá a perfuração do material, pois a quantidade de zinco disponível também não é suficiente para proteger catodicamente $o$ aço nas regiões danificadas da película de tinta.

Pela aparência dos corpos-de-prova, após quatro anos de teste não-acelerado de corrosão, com exposição em atmosfera marinha, constata-se, além da influência da espessura da camada de zinco na resistência à corrosão dos aços eletrogalvanizados, o melhor desempenho dos aços com substratos de aço USI-R-COR-III comparativamente aos de aço carbono convencional, principalmente nas regiões de risco, bordas e furação (Figuras 7 e 8 ). 


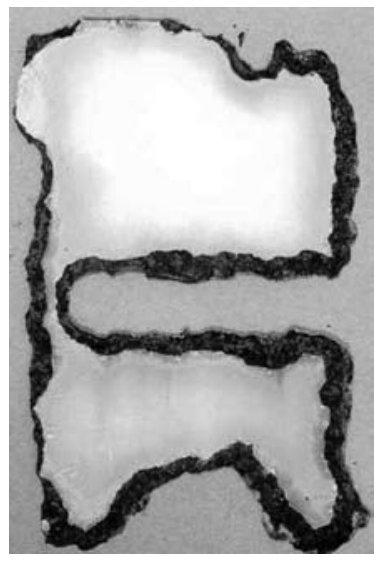

(a)

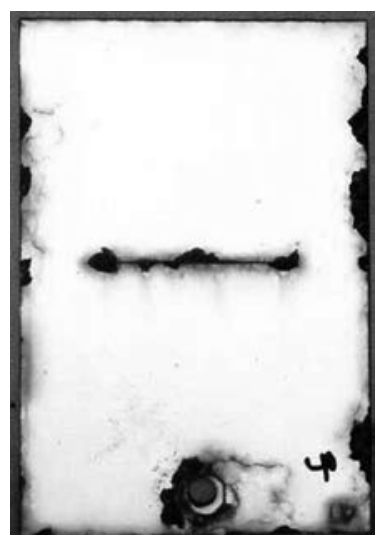

(b)

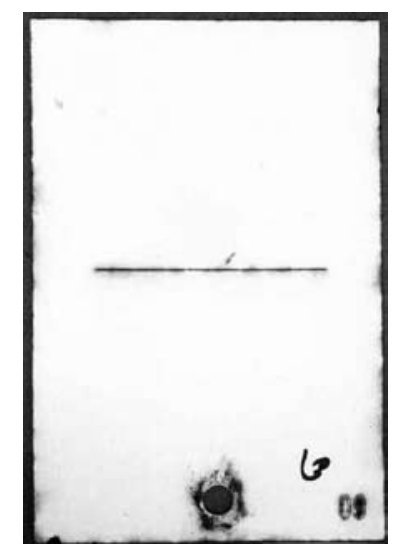

(c)

Figura 7. Aspectos dos corpos-de-prova com substrato metálico de aço carbono convencional, após quatro anos de teste não-acelerado de corrosão com exposição em atmosfera marinha. a) Carbono convencional; b) Usigalve $40 / 40 \mathrm{~g} / \mathrm{m}^{2}$; e c) Usigalve $60 / 60 \mathrm{~g} / \mathrm{m}^{2}$.

\section{CONCLUSÕES}

Deste estudo, conclui-se que a massa de camada de zinco exerce papel preponderante na resistência à corrosão dos aços eletrogalvanizados, fosfatizados e pintados. Ademais, a utilização de substratos metálicos com características de resistência à corrosão também contribui para o aumento da resistência à corrosão atmos-

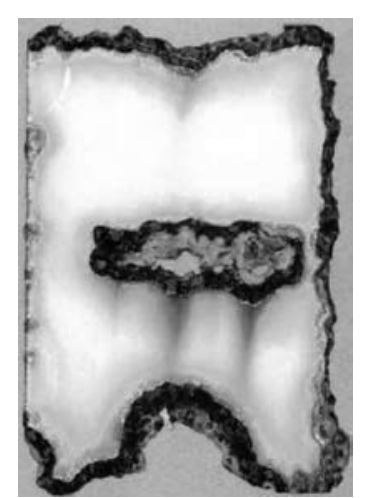

(a)

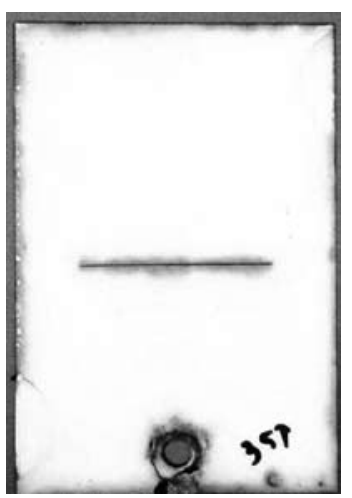

(c)

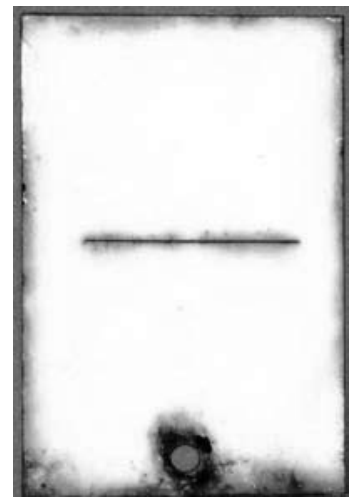

(b)

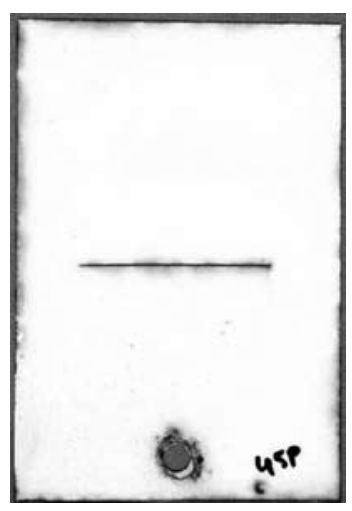

(d)
Figura 8. Aspectos dos corpos-de-prova com substrato metálico de aço USI-R-COR-III, após quatro anos de teste não-acelerado de corrosão com exposição em atmosfera marinha. a) USI-R-COR-III; Usigalve/Plus $20 / 20 \mathrm{~g} / \mathrm{m}^{2}$; Usigalve/Plus $30 / 30 \mathrm{~g} / \mathrm{m}^{2}$; e Usigalve/Plus $40 / 40 \mathrm{~g} / \mathrm{m}^{2}$.

férica dos aços eletrogalvanizados. A redução pura e simples da massa da camada de zinco não é uma boa opção, pois dependendo da quantidade de zinco escolhida, a resistência à corrosão dos aços revestidos com zinco é inferior a dos aços com características de resistência à corrosão atmosférica e sem esse revestimento .

O aumento da resistência à corrosão, proporcionado pelo substrato metálico dos aços Usigalve/Plus (aço USI-R-COR-III), permite reduzir a massa de zinco desses aços até que sua resistência à corrosão iguale a dos aços Usigalve de maior massa de zinco e fabricados com substrato de aço carbono convencional. A utilização de aços Usigalve/Plus com menor espessura de camada de zinco propiciaria um incremento na conformabilidade dos aços eletrogalvanizados.

Finalmente, para esquemas de pintura semelhantes ao utilizado nesse estudo podem ser empregadas as curvas apresentadas nas Figuras 7 e 8 , como referência de cálculo da espessura da camada de zinco; caso contrário, é necessária a construção de tais curvas. 


\section{REFERÊNCIAS}

I VAN WESEMAEL, J. A performance evaluation of modern surface finishes for zinc die castings. DIE-CASTING ENGINEER, v. 47, n. 2, p. 26-7, Mar. 2003.

2 HISAMOTO, J.; IKEDA, K.; SATOH, H. Aspects of peeling behavior of electrogalvanized steel sheets with emphasis on coating hardness. Kobelco Technology Review, n. II, p. 33-37, Jun. 1991.

3 URAI, M.; IWAYA, J.; ARIMURA, M.; SAKAI, H.; MIYAHARA, M. Effects of forming conditions on exfoliation of galvannealead steel sheets. Kobelco Technology Review, n. II, p. 38-42, June I99I.

4 CÁRCEL, A.C.; FERRER-GIMÉNEZ, C.; GONZALO, G. Determinación experimental de los factores que controlan el desprendimiento de polvos en el conformado de chapas de acero recubiertas con Zn-Ni. Revista de Metalurgia, v. 3I, n. 2, p. 79-88, 1995.

5 PEREIRA, J.F.B.; ALVARENGA, E.A.; BARCELOS, H. Influência de revestimentos metálicos no valor "r" de Lankford de aços laminados à frio. In: SEMINÁRIO DE LAMINAÇÃO - PROCESSOS, PRODUTOS LAMINADOS E REVESTIDOS, 32., 1995, Curitiba. Anais... São Paulo: ABM, 1995. p. 443-448.

6 KIKUCHI, K.; ISOBE, M.; KATO, C.; UCHIDA, M. Corrosion of the vehicles used in North America: anti-corrosion performance of galvanized steel sheet in several parts of vehicle. JSAE - SOCIETY OF AUTOMOTIVE ENGINEERS OF JAPAN, v. 22, n. 2, p. 205-210, 2001.

7 ALVARENGA, E.A.; BUONO, V.T. L. Influência do substrato metálico na resistência à corrosão de aços eletrogalvanizados fosfatizados e pintados. In: $60^{\circ}$ CONGRESSO ANUAL DA ABM, 60., 2005, Belo Horizonte. Anais... São Paulo: ABM, 2005.

8 YASUDA, A.; UMINO, S.; KYONO, K; YAMATO, K. Cosmetic corrosion of Zn Alloy coated sheet steels. In: WORLD MATERIALS CONGRESS - CORROSION RESISTANT AUTOMOTIVE SHEET STEELS, 1988, Chicago. Proceedings... [S.I: s.n.], 1988. p. 31-37.

9 MIYOSHI, Y.; OKA, J.; MAEDA, S. Fundamental research on corrosion resistance of precoated steel sheets for automobiles. Transaction of the Iron and Steel Institute of Japan, v. 23, n. II, p. 974-983, 1983.

Recebido em: 26/12/06

Aceito em: 27/I I/07

Proveniente de: SEMINÁRIO DE LOGÍSTICA, 25., 2006, Santos, SP. São Paulo: ABM, 2006. 